Western University Scholarship@Western

1981

\title{
Price Dispersion and Stockpiling by Consumers
}

Sam Bucovetsky

Follow this and additional works at: https://ir.lib.uwo.ca/economicsresrpt

Part of the Economics Commons

Citation of this paper:

Bucovetsky, Sam. "Price Dispersion and Stockpiling by Consumers." Department of Economics Research Reports, 8108. London, ON: Department of Economics, University of Western Ontario (1981). 
ISBN: $0-7714-0265-1$

\section{RESEARCH REPORT 8108}

\section{PRICE DISPERSION AND STOCKPILING}

BY CONSUMERS

by

Sam Bucovetsky

Revised (and corrected) version

May, 1981 


\section{Introduction}

Recently, several models involving imperfect information have been presented in which price dispersion occurs in equilibrium. ${ }^{1}$ Here yet another such model is presented. The major justification for such an exercise is that violations of the law of one price seem frequent. Quite apart from the intellectual satisfaction of explaining hitherto unexplained phenomena, these models often provide new and different implications for policy. In section 9 below I show how the effects of parameter changes in a simple version of my model may be "perverse". Also, the model presented here may provide a useful framework for analysis of issues ${ }^{2}$ other than the existence of price dispersion.

Most recent models of price dispersion involve demand curves differing among sellers. If there is costly search, sellers who have a reputation for 10w prices attract more buyers. Thus the demand curve for sellers who choose to attract those for whom search is cheap is further out than that for sellers who expect to attract only those for whom search is costly. Alternatively, Reinganum (1979) has presented a model in which all sellers face identical demand curves, but differ in their costs. The significance of these differences among sellers is as follows. Suppose sellers act as monopolistic competitors. Then in long-run equilibrium they will operate where their perceived demand curves are tangent to their average cost curves. For there to be multiple prices observed in equilibrium, then either sellers must differ somehow, or there must be multiple tangencies of the demand and average cost curves.

In the model presented here there may be such multiple tangencies. This possibility may seem an unlikely coincidence, which can be removed by sma11 parameter changes. However here the demand curves are endogenously generated by the observed price distribution. And a property of the equilibrium price 
distribution is that the demand curves it generates be tangent to sellers' cost curves at several points.

The reason for the endogeneity of demand curves is that buyers can store goods. Storage by buyers of some commodities is frequently observed. Such storage is costly, since it takes up space and requires funds which could be invested elsewhere. So any storage beyond that required in the period until the next purchase seems irrational in equilibrium. Yet when "bargains" are encountered, buyers often stock up for future consumption. Presumably this is because they do not expect to encounter as low a price the next time they visit the market. There is an optimal rule for such stockpiling, and it depends on buyers' perceptions of future prices. This rule generates buyers' demands, which in turn determine the prices charged by sellers. What will be shown is that in equilibrium, more than one price may be charged.

\section{Optima1 Stockholding}

Consider first a buyer's optimal stockholding problem. To simplify, I will assume underlying demand is inelastic, up to a "reservation price". A buyer consumes exactly one unit of the commodity if its price is less than or equal to $\mathrm{p}_{\max }$, and nothing otherwise. This assumption is common to many of the search models, ${ }^{3}$ and does not qualitatively affect the results. The commodity can be purchased at discrete intervals ("shopping trips"); units have been normalized so that consumption between purchases is exactly 1 unit. Since demand is inelastic, the buyer's problem is to minimize the present value of the expected cost of his consumption. Let $V(z, p)$ denote this minimal value. It is a function of $z$, the buyer's current stock of the commodity and $p$, the price he has just encountered. It also depends on the perception of the distribution of the prices to be encountered in the future. 4 
Since the buyer has just encountered the price $p$, his optimization involves choosing how much of the commodity to purchase at that price. Purchases must be non-negative, and consumption between now and the next purchase must equal 1 unit (if $\mathrm{p} \leq \mathrm{p}_{\max }$ ). This second requirement means current purchases must be at least $1-z$. Let $s()$ be the storage cost function $(s(x)$ is the cost of storing $x$ units for 1 period). I assume $s(0)=0$, s everywhere differentiable and $s \geq 0, s^{\prime}>0, s^{\prime \prime} \geq 0$. Let $\delta(0<\delta \leq 1)$ be the discount factor. Then the buyer's problem is

$$
\min p \cdot x+s(x+z-1)+\delta E[V(x+z-1, \cdot)] \quad \text { subject to } x \geq 0, x+z \geq 1
$$

In a stationary environment, then,

$$
\text { (1) } \quad \mathrm{V}(\mathrm{z}, \mathrm{p})=\min _{\mathrm{x} \geq 0 \mathrm{x} \geq 1-\mathrm{z}}\{\mathrm{px}+\mathrm{s}(\mathrm{x}+\mathrm{z}-1)+\delta \mathrm{E}[\mathrm{V}(\mathrm{x}+\mathrm{z}-1, \cdot)]\}
$$

The expectation on the right is over the buyer's perceived distribution of prices next period. Implicit here is that the buyer's current encounter with a price $\mathrm{p}$ does not enable him to encounter this price next period. Each period's price is viewed as a random draw from some distribution $F()$. Either the buyer cannot remember reputations of individual sellers, or sellers have random pricing strategies. I return to this issue below in section 8 . But it should be noted that this "idiot-savant" aspect of buyer behavior (knowing F( ) but not remembering where he was) is not as extreme as might be thought. The distribution of prices will often have a very simple form in equilibrium. The buyer's optimization yields his demand for the commodity as a function of $2, p$ and his perception of the price distribution. This demand will be a negatively-sloped function of the price $p$, despite the inelastic nature of current consumption demand. Not surprisingly, low current prices give rise to higher demand because of the possibility of storage for future consumption. 
Unfortunately an explicit derivation of this demand is quite a messy exercise. The culprit is the discrete nature of buyers' purchases, which causes jumps in the demand function. At integer levels of planned storage $(x+z-1)$ the buyer jumps from storing for $n$ periods to storing for $n+1$ periods.

To begin, let me divide $z$ - p space into 3 regions, depending on which of the constraints in (1) is binding. In region 1 an interior solution to the optimization exists. In region 2, the constraint $x+z \geq 1$ is binding. For $(z, p)$ to be in region 2 , existing stocks must be inadequate for current consumption, so that $z \leq 1$. In region 3, the constraint $x \geq 0$ is binding (but not the constraint $x+z \geq 1)$, so that $z \geq 1$ if $(z, p)$ is in region 3 .

If there is a finite maximm price in the perceived distribution, then regions 2 and 3 are non-empty. For if this period's price $p_{0}$ is so high that $\delta \mathrm{p}_{1}<\mathrm{p}_{0}+\mathrm{s}^{\prime}(0)$ for al1 possible prices $\mathrm{p}_{1}$ next period, then it is better to postpone purchases (if possible). There also exists some function $p *(z)$ which marks the boundary between regions 2 and 3 on the one side, and region 1 on the other. Not surprisingly, lower values of $p\left(p<p^{*}(z)\right)$ imply $(z, p)$ is in region 1. To prove this formally, note that if $\left(z_{0}, p_{0}\right)$ is in region 1 and $z_{0}>1$, then there is some $x>0$ such that $p_{0} x+s\left(x+z_{0}-1\right)+\delta E\left[V\left(x+z_{0}-1, \cdot\right)\right]$ $<s\left(z_{0}-1\right)+\delta E\left[V\left(z_{0}-1\right), \cdot\right]$ Then if $p_{1}<p_{0}, p_{1} x+s\left(x+z_{0}-1\right)+\delta E\left[V\left(x+z_{0}-1, \cdot\right)\right]$ $<s\left(z_{0}-1\right)+\delta E\left[\left(V\left(z_{0}-1\right), \cdot\right]\right.$ so that $\left(z_{0}, p_{1}\right)$ is in region 1. Similarly, if $\left(p_{o}, z_{0}\right)$ is in region 1 and $z_{0} \leq 1$, then $p_{1} x+s\left(x+z_{0}-1\right)+\delta E\left[V\left(x+z_{0}-1, \cdot\right)\right]$ $<\mathrm{p}_{0} \mathrm{x}+\mathrm{s}\left(\mathrm{x}+\mathrm{z}_{\mathrm{o}}-1\right)+\delta \mathrm{E}\left[\mathrm{V}\left(\mathrm{x}+\mathrm{z}_{\mathrm{o}}-1, \cdot\right)\right]<\mathrm{p}\left(1-\mathrm{z}_{\mathrm{o}}\right)+\delta \mathrm{E}[\mathrm{V}(0, \cdot)]$ for some $\mathrm{x}>1-\mathrm{z}$, if $\mathrm{p}_{1}<\mathrm{p}_{0}$. Finally, note that the boundary $\mathrm{p}^{*}(\mathrm{z})$ between regions 1 and 2 is independent of $z$ when $z<1$. This result is because $(z, p)$ is in region 2 if $z<1$ and $p(1-z)+\delta E[V(0, \cdot)]<p x+s(x+z-1)+\delta E[V(x+z-1, \cdot)]$ for all $x>1-z$. 
But if $y$ is defined as $x+z$, this inequality can be written $p(1-z)+\delta E[V(0, \cdot)]$ $<p(y-z)+s(y-1)+\delta E[V(y-1, \cdot)]$ for al1 $y>0$, or $p+\delta E[V(0, \cdot)]$ $<p y+s(y-1)+\delta E[V(y-1, \cdot)]$ for all $y-0$, which condition does not depend on z. Therefore, the optimization by the buyer must divide $(z, p)$ space as in figure 1. However, the reader is forewarned that it will be shown immediately that the $p^{*}(z)$ curve cannot slope up as in figure 1.

If $(z, p)$ is in region 1 , then the optimal purchase $x$ of the commodity must satisfy

$$
p+s^{\prime}(x+z-1)+\delta E\left[V_{1}(x+z-1, \cdot)\right]=0
$$

(where subscripts refer to partial derivatives). From equations (1) and (2), if $(z, p)$ is in region 1 , then

$$
v_{1}(z, p)=-p
$$

Equation (3) also holds if $(z, p)$ is in region $2 .^{5}$ Hence if the purchase $x$ is such that $x+z-1<1$, then $\delta E\left[V_{1}(x+z-1, \cdot)\right]=\delta \hat{p}$, where $\hat{p}$ is the expected price. Therefore the equation of the boundary $p^{*}(z)$ between regions 1 and 2 is

$$
p *(z)+s^{\prime}(0)=\delta \hat{p} \quad \text { for } z<1
$$

(For 1 ow enough $\hat{\mathrm{p}}$, and high enough $s^{\prime}(0)$, region 1 may be empty).

To extend $p *$ to higher values of $z$, consider first stocks between 1 and 2. If the optimal purchase is precisely 0 (i.e., $(z, p)$ is on the border between regions 1 and 3$)$, then $p+s^{\prime}(z-1)+\delta E\left[v_{1}(z-1, \cdot)\right]=0$. But if $z \in(1,2)$, then $z-1<1$. Therefore $E\left[V_{1}(z-1, \cdot)\right]=\hat{p}$, and so the equation for $p^{*}$ can be written

$$
p^{*}(z)+s^{\prime}(z-1)=\delta \hat{p} \quad \text { for } z \epsilon(1,2)
$$

This implies $p^{*}$ is continuous at $z=1$ (see (4) above). Also, 


$$
\frac{d p^{*}}{d z}=-s^{\prime \prime}(z-1) \leq 0 \quad \text { for } z \in(1,2)
$$

so that $\mathrm{p}^{*}$ slopes down, or is horizontal if the storage function is linear. However, although $V_{1}=-p$ in regions 1 and 2 , this equality does not hold in region 3. There $V_{1}=s^{\prime}(z-1)+\delta E\left[V_{1}(z-1, \cdot)\right]=-p^{*}(z)>-p$. Thus the derivative $v_{1}$ jumps as the line $z=1$ is crossed, moving from region 2 to 3 . If $z-1>1$, then $E\left[V_{1}(z-1, \cdot)\right]=-\int_{0}^{F(p *(z-1))} p d p-\left(1-F\left(p^{*}(z-1)\right) p^{*}(z-1)>-\hat{p}\right.$. The curve $p^{*}(z)$ has been defined as the set of $p$ such that the first-order condition (2) is satisfied for $x=0$. Therefore at $z=2, p^{*}$ jumps downward, from $\delta \hat{p}-s^{\prime}(1)$ to $\delta \int_{0}^{F\left(p^{*}(1)\right)} \operatorname{pdp}+\delta\left(1-F\left(p^{*}(1)\right) p^{*}(1)-s^{\prime}(1)\right.$. For $z \epsilon(2,3)$, the $p^{*}$ curve is again a continuous downward-sloping curve, whose equation is

$$
\text { (7) } \quad p^{*}(z)+s^{\prime}(z-1)=\delta\left[\int_{0}^{F(p *(z-1))} p d p+\left(1-F\left(p^{*}(z-1)\right) p^{*}(z-1)\right]\right.
$$

where $p *(z-1)$ is defined from equation (5). The slope of this curve is

$$
\frac{d p^{*}}{d z}=-s^{\prime \prime}(z-1)-\delta\left(1-F\left(p^{*}(z-1)\right) \frac{d p^{*}(z-1)}{d(z-1)} \leq 0\right.
$$

One can define $p^{*}(z)$ for all $z>2$ recursively, using equation (7). At each integer value of $z$ there will be downward jumps "echoing" the jump at $z=1$, due to the jump in $\mathrm{p}^{*}(z-1)$ on the right-hand side of (7). Between integer values, the curve $\mathrm{p}^{*(z)}$ slopes downward. Figure 2 illustrates this. Note that equation (7) implies $p^{*}(z) \leq \delta p^{*}(z-1)-s^{\prime}(z-1)$, so that the $p^{*}$ curve must fall by at least $s^{\prime}(0)$ over each unit interval. If there is some upper bound $\overline{\mathrm{p}}$ such that no possible price distribution has any prices observed higher than $\bar{p}$, then the $\mathrm{p}^{*}$ curve must cross the $\mathrm{p}$-axis before $\mathrm{z}=\overline{\mathrm{p}} / \mathrm{s}^{\prime}(0)$. Below it will be argued that all equilibrium price distributions can be bounded in this way.

The final step in calculating a buyer's demand is to derive how much he will buy if he is unconstrained. But this is quite simple. Note that equation (2) is in terms of next period's desired stock $x+z-1$. The buyer's purchase 
$x(p, z)$ should be $z *(p)-z$, where

$$
p+s^{\prime}(z *(p)-1)+\delta E\left[V_{1}(z *(p)-1, \cdot)\right]=0
$$

of course $z^{*}(p)$ is just the inverse function to $p^{*}(z) .^{6}$ The buyer should use a price-based inventory rule. If current stocks $z$ are less than desired stocks $z *(p)$, the buyer should buy enough to bring stocks up to $z^{*}(p)$. If they exceed $z^{*}(p)$ he should buy nothing, unless he needs to buy something for immediate consumption $(z<1)$. Thus if $(z, p)$ is in region 1 , he buys $z *(p)-z$. In region 2 he buys $1-z$. In region 3 he buys nothing.

3. The Demand Function

For a buyer with a given initial stock $z$, demand will have a perfectly inelastic portion and a more elastic portion. If $z>1$, then demand will be zero for $p>p^{*}(z)$, and $z^{*}(p)-z$ for $p \leq p^{*}(z)$. If $z<1$, demand is $1-z$ for $p>\delta \hat{p}-s^{\prime}(0)$, and $z *(p)$ for $p \leq \delta \hat{p}-s^{\prime}(0)$. Of course it should be emphasized that both the expected price $\hat{p}$, and the optimal stock $z *(p)$ depend on the buyer's perception of the price distribution. This was precisely what was meant by the statement in the introduction that demand curves were endogenously generated.

In equilibrium buyers' perceptions are correct. This implies that they are the same for all buyers. Suppose further that the reservation price $\mathrm{P}_{\max }$, the storage function $s()$, and the discount factor $\delta$ are also identical. Then the only variable which may differ across consumers is their initial stocks z. Let $G()$ be the distribution for these stocks. ${ }^{7}$ Then the aggregate demand curve $D($ ) has the equation

$$
\begin{array}{ll}
D(p)=\int_{0}^{z^{*}(p)}\left(z^{*}(p)-z\right) d G(z) & \text { for } p<\delta \hat{p}-s^{\prime}(0) \\
D(p)=\int_{0}^{1}(1-z) d G(z) & \text { for } p_{\max } z p \geq \delta \hat{p}-s^{\prime}(0)
\end{array}
$$


The demand curve inherits the jumps in the $p *$ curve of figure 2 . If $p$ lies within one of the jumps of figure 2 (i.e., $\lim p^{*}(z)>p>\lim p^{*}(z)$ for some integer $z$ ), then quantity demanded will not vary with price. The height of the vertical drop in the demand curve is the same as in the p* curve. The location of the drops (the abscissae) are no longer at integer values; equation (10) shows they are at values of $D$ equal to $\int_{0}^{n}(n-z) d G(z)$ for some integer $n$.

I assume that each seller gets an identical distribution of customers. That is, if there are $\frac{P}{m}$ sellers and $P$ buyers the stocks of each seller's buyers are distributed as $\mathrm{mG}()$. Thus each store's demand curve is $\mathrm{mD}()$, where $\mathrm{D}$ is defined as in equation (10). It is as if each period buyers choose a seller at random. Having chosen the seller, they observe the price, make their purchases. according to the optimal rule, and move on to another randomly chosen seller in the next period. Thus there is very little competition in the "monopolistically competitive" market described here. Nothing sellers do can attract buyers from one seller to another. Each seller has complete monopoly power over his segment of the market. However, I do rely rather heavily--as will be seen below--on another aspect of monopolistic competition, the zero profit condition. Since each seller is a monopolist, none will ever operate in the perfectly inelastic portion of the demand curve. If a price greater than $\delta \hat{\mathrm{p}}-\mathrm{s}^{\prime}(0)$ is charged, it must be $\mathrm{p}_{\max }$, the reservation price. In equilibrium, perceptions are correct, so that $\hat{\mathrm{p}}$ is the actual mean of the observed price distribution. Some prices greater than $\delta \hat{p}-s^{\prime}(0)$ must be observed for $\hat{p}$ to be the mean. Hence in any equilibrium the reservation price $\mathrm{p}_{\max }$ will be encountered with positive probability. This result can be generalized to more elastic underlying demand, or to varying reservation prices among buyers. It will still be the case that 
in equilibrium a positive fraction of the sellers will charge the monopoly price. For in equilibrium, the seller charging the highest observed price will be able to sell only for current consumption. Why stockpile when the probability of observing at least as low a price next period is 1 ? Therefore the sellers charging the highest price face the underlying demand curve for current consumption, and will charge the monopoly price. ${ }^{8}$ Unlike search models, the storage model cannot eliminate the possibility of observing the monopoly price.

A lower bound for the fraction of sellers charging the monopoly price can also be obtained (for the simple model with identical reservation prices). Since all observed prices other than the monopoly price must be less than $\delta \hat{\mathrm{p}}-\mathrm{s}^{\prime}(0)$, therefore $\hat{\mathrm{p}}<\alpha \mathrm{p}_{\max }+(1-\alpha)\left(\delta \hat{\mathrm{p}}-\mathrm{s}^{\prime}(0)\right)$, where $\alpha$ is the fraction of

sellers charging the monopoly price. If $\hat{\mathrm{p}}$ is positive, $\frac{\alpha}{1-\alpha}>\frac{\mathrm{s}^{\prime}(0)}{\delta \mathrm{p}_{\max }}$. If the marginal costs of storage (for one period) exceed the reservation price, at least half the sellers must charge the monopoly price. As can be seen this is quite a weak bound. In fact, there may well be an equilibrium with only the monopoly price charged.

\section{Equilibrium Conditions}

The distribution $G($ ) of stocks held by buyers is itself endogenous. In equilibrium it will be stationary. If a buyer has stocks of $z$ or less this period, then last period he must have (a) stocks of $z+1$ or less and (b) encountered a price which was so high he chose not to buy. Therefore

$$
G(z)=G(z+1)\left(1-F\left(p^{*}(z+1)\right) \quad \text { for } z>0\right.
$$

At integer values of $z$, the price $p^{*}$ is not uniquely defined. But since the demand curve is perfectly inelastic there, in equilibrium only the highest value of $\mathrm{p}^{*(z)}$ will be observed. Thus there is no difficulty in defining $F$. 
Equation (11) implies 1 im $G(z)>0$. There is an atom for the distribution $G$ $\mathrm{z} \rightarrow 0$

at $z=0$, consisting of all buyers who encountered a price of $P_{\max }$ and had stocks on hand of 1 or less.

$$
\mathrm{dG}(0)=\mathrm{G}(1) \mathrm{dF}\left(\mathrm{p}_{\max }\right)
$$

The steady-state distribution of stocks $G($ ) can be recursively computed for any price distribution. Above it was noted that if an upper bound existed on observed prices, then a finite $z$ existed for which $p^{*}(z)=0$. And if there is only one reservation price (or only a finite number of them), no seller will charge a price higher than $\mathrm{P}_{\max }$ in equilibrium. Thus for $z>z_{\max }=\mathrm{p}_{\max } / \mathrm{s}^{\prime}(0)$, $F\left(p^{*}(z)\right)=0$, so that $G(z)=1$ for $z>z_{\max }$. Therefore, after equations (5) and (7) have been used to solve for $\mathrm{p}^{*}$, then (11) can be used to calculate G( ), starting at $G\left(z_{\max }\right)=1$. The demand function resulting (by plugging $\mathrm{p}^{*}, G()$ into equation (10)) will be continuous if $z^{*}$ is well-defined and continuous. If $s^{\prime \prime}=0$, so that $z^{*}$ is multiple valued, then $D$ will be a multi-valued correspondence, but well-behaved (i.e., upper hemi-continuous, and closed- and convex-valued). These constnuctions and allegations will be used in the formal existence proof below.

In equilibrium, prices actually charged must maximize sellers' profits, and must yield zero profits. I assume the number of sellers is large, so that each treats the distribution of prices as given. Thus a seller contemplating a price change does not expect the perceived distribution by buyers $F()$ to be affected by its actions. Also the number of buyers per seller is taken as given. Potential entrants do not expect to change the value of $m$. Let $q(p)$ be the inverse of the sellers' average cost function which is assumed downwardsloping. Then profits will be positive at a price $p$ if and only if $m D(p)>q(p)$. 
Thus an equilibrium condition is that $\mathrm{mD}(\mathrm{p})=\mathrm{q}(\mathrm{p})$ if $\mathrm{p}$ is actually charged, and $m D(p) \leq q(p)$ for all $p$. Since the reservation price $p_{\max }$ must be charged in equilibrium,

$$
\mathrm{m} \int_{0}^{1}(1-z) d G(z)=q\left(p_{\max }\right)
$$

For this to occur, a necessary condition is

(A) $\quad \mathrm{q}\left(\mathrm{p}_{\max }\right)>0$

Otherwise entry could not drive high-priced sellers' profits to zero. Summarizing, an equilibrium consists of a price distribution $F()$, a distribution of buyers' stocks $G()$, and a buyer-seller ratio $m$ such that

(i) buyer perceptions are correct: all stockpiling decisions are made using the actual distribution $\mathrm{F}($ )

(ii) the distribution of stocks $G($ ) conforms to the optimal stockpiling decision (i.e., equations (11) and (12) hold)

(iii) non-positive profit: $\mathrm{mD}(\mathrm{p}) \leq \mathrm{q}(\mathrm{p})$ for all prices $\mathrm{p}$, where demand $\mathrm{D}$ is defined by equation (10)

(iv) no losses: if $F$ jumps at $p$, or if $F$ is differentiable at $p$ and $F^{\prime}(p)>0$, then $q(p)=m D(p)$.

What has been demonstrated so far is that any equilibrium must involve the price $\mathrm{p}_{\max }$ occurring with positive probability. Three outcomes are possible: an equilibrium where only the reservation price $\mathrm{p}_{\max }$ occurs; a multiple price equilibrium; or no equilibrium at all. In section 7 below it will be proved formal1y that an equilibrium must exist. However, prior to that, it will be shown that one- or two-price equilibria do exist. 


\section{A One-Price Equilibrium}

The existence of a one-price equilibrium is hardly surprising. If storage costs are high enough sellers will not lower prices sufficiently to induce purchases for future use. Given the complete monopoly power each seller has, they will all charge the monopoly price. What is a necessary and sufficient condition for such a situation is that no potential entrant be able to charge a lower price and make a profit. This non-profitability condition can be written $m D(p) \leq q(p)$ for all $p$. But $D$ depends on the price distribution. If only the monopoly price is being charged, $\mathrm{F}=0$ for all $\mathrm{p}<\mathrm{p}_{\max }$ and $\mathrm{F}\left(\mathrm{p}_{\max }\right)=1$. This distribution implies that $G()$, the distribution of stocks, also is a step function. No one will carry any stocks, since there is no uncertainty about next period's price. Thus total demand at any price $p$ is $P$ (on the vertical upper portion of the curve) or $z^{*}(\mathrm{p}) \mathrm{P}$. The price at which buyers begin to stockpile is $\mathrm{p}^{*}(1)$. Since the average price $\hat{\mathrm{p}}$ is just $\mathrm{p}_{\max }$, then $\mathrm{p}^{*}(1)=\delta \mathrm{p}_{\max } \mathrm{s}^{\prime}(0)$. . Below this price the inverse of the demand curve $\mathrm{p}^{*}(\mathrm{z})$ can be defined by

$$
\begin{aligned}
p^{*}(z) & =\delta p_{\max }-s^{\prime}(z-1) & & 1 \leq z \leq 2 \\
& =\delta p^{*}(z-1)-s^{\prime}(z-1) & & z>2
\end{aligned}
$$

The buyer-seller ratio $m$ must yield zero profits for stores charging the monopoly price, so

$$
\operatorname{ac}(m)=p_{\max } \quad \text { or } \quad q\left(p_{\max }\right)=m
$$

The condition that no potential entrant make profits is that price as defined using (14) be less than or equal to average cost, or

$$
\operatorname{ac}(m z) \geq p *(z) \quad \text { or } \quad q(p) \geq m z^{*}(p)
$$

where $\mathrm{p}^{*}$ is defined by (14). 
If equation (16) does not hold for all $\mathrm{p}$, then there can be no one-price equilibrium. Since there are profit-making opportunities for some new entrant, such entry may suggest an equilibrating process. Entry at prices below $\mathrm{p}_{\max }$ might be expected to move the demand curve inward, until eventually a multiple tangency results. But there are problems with such a process. If some price $\mathrm{p}$ is profitable in the initial one-price situation, so may other prices be in a neighbourhood of p. Many patterns of entry are certainly possible. And in the new equilibrium it is not just non-positive profits that are required. It must be ensured that all prices actually observed are associated with zero profits. In addition, it is not necessarily true that more low-priced sellers must lower profits of all potential entrants. It is certainly true that entry at a price below $\mathrm{P}_{\max }$ must lower the aggregate demand curve. But this in turn will induce exit by high-priced sellers, so that the zero-profit condition (13) for high-priced sellers can be restored. It may well be that the reduction in the seller-buyer ratio induced by entry at some low price actually increases the profitability of entry at some prices.

\section{A Two-Price Equilibrium}

Although no equilibrating process will be put forward here, conditions will be presented in which a two-price equilibrium does exist. The main difficulty in the analysis is the presence of jumps in the demand function. To minimize complications, strong conditions will be presented which ensure that the lower price $p$ in equilibrium is such that $z^{*}(\mathrm{p})<2$. The main purpose of this section is to demonstrate that equilibria involving a discrete price distribution should be expected in this model.

Suppose the storage function $s$ is quadratic. Suppose also that the inverse average cost function $q$ is convex. Since a one-price equilibrium exists 
when entry is not profitable, assume there is some price p such that profits could be made if only the monopoly price were charged. Finally, to avoid the jumps at integer levels of stockpiling, assume it is never optimal to store more than 1 period ahead. Formally these assumptions can be written

$$
\begin{aligned}
& s^{\prime \prime \prime}=0: q^{\prime \prime}>0 \\
& \quad \operatorname{ac}\left[q\left(p_{\max }\right) z\right]<\delta p_{\max }-s^{\prime}(z-1) \quad \text { for some } z<2 \\
& p_{\min } \equiv \lim _{q \rightarrow \infty} \operatorname{ac}(q) \geq \delta p_{\max }-s^{\prime}(1)
\end{aligned}
$$

A two-price equilibrium is defined by 3 variables:

$\alpha$ : the proportion of sellers charging $\mathrm{p}_{\max }$

p: the price charged by the other $(1-\alpha)$ sellers

$\mathrm{m}$ : the buyer-seller ratio

Since demand, and optimal storage, depend on the distribution, this will be noted explicitly by writing $D\left(p ; \alpha, p^{\prime}\right)$, and $z\left(p ; \alpha, p^{\prime}\right)$ for the demand and storage functions when $\left(\alpha, p^{\prime}\right)$ is the distribution. Some further notation:

$$
\begin{aligned}
& \tilde{D}(p, \alpha)=D(p ; \alpha, p) \\
& \tilde{z}(p, \alpha)=a(p ; \alpha, p)
\end{aligned}
$$

In other words, $\tilde{D}$ is the demand at the price actually observed a proportion $(1-\alpha)$ of the time.

Suppose now a price $\mathrm{p}^{\prime}$ is charged a proportion $(1-\alpha)$ of the time. Then a proportion $\alpha$ of buyers will have no stocks on hand, and a proportion $1-\alpha$ have stocks $\tilde{z}\left(p^{\prime}, \alpha\right)-1$ (if $2>\tilde{z}\left(p^{\prime}, \alpha\right)>1$ ). Therefore demand at any price $p$ can be written

$$
D\left(p ; \alpha, p^{\prime}\right)=m\left[\alpha z *\left(p ; \alpha, p^{\prime}\right)+(1-\alpha)\left(z *\left(p ; \alpha, p^{\prime}\right)-\tilde{z}\left(p^{\prime}, \alpha\right)+1\right)\right]
$$


It follows that the slope $\frac{\partial z^{*}}{\partial p}$ of the demand curve is

(18) $\frac{\partial D}{\partial p}=m \frac{\partial z *}{\partial p}$

Demand for the high-priced seller will be: 1 unit from the $\alpha$ buyers who have no stocks on hand; $1-[(\tilde{z}(p, \alpha)-1]$ units from those who have stocks. Since these sellers make zero profits, the buyer-seller ratio $m$ can be defined from

$$
q\left(p_{\max }\right)=m[\alpha+(1-\alpha)(2-\tilde{z}(p, \alpha)]
$$

Next, from the definition (5) of the optimal $z^{*}$

$$
p+s^{\prime}\left[z^{*}\left(p ; \alpha, p^{\prime}\right)-1\right]=\alpha \delta p_{\max }+(1-\alpha) \delta p^{\prime}
$$

also implying

$$
[1-(1-\alpha) \delta] p+s^{\prime}\left(z^{\sim}(p, \alpha)-1\right)=\alpha \delta p_{\max }
$$

From (21), there is a lower bound on the feasible $\alpha$ 's; if $\alpha=0 \mathrm{p}<0$. Also (21) implies $\frac{\partial \widetilde{z}}{\partial \mathrm{p}}<0$ and $\frac{\partial \widetilde{z}}{\partial \alpha}>0$. By assumption, $\mathrm{z}^{*}\left(\mathrm{p} ; \alpha, \mathrm{p}^{\prime}\right)<2$ for a11 $\mathrm{p}>\mathrm{p}_{\min }$ (since $\mathrm{p}_{\min }>\delta \mathrm{p}_{\max }-\mathrm{s}^{\prime}(1),(20)$ can never hold with $z^{*}=2$ ).

The equilibrium sought can be depicted in figure 3. The boundaries of the feasible region are $p=p_{\text {min }}, \alpha=1$, and $\tilde{z}(p, \alpha)=1$. Since $\frac{\partial \widetilde{z}}{\partial p}<0$ and $\frac{\partial \widetilde{z}}{\partial \alpha}>0$, the latter curve must slope up. From equation (20)

$$
\frac{\partial z^{*}}{\partial p}=-\frac{1}{s^{\prime \prime}}
$$

Therefore the conditions that profits be zero, and the demand curve $D\left(p ; \alpha, p^{\prime}\right)$ be tangent to the cost curve at $p=p^{\prime}$ can be written as

$$
\begin{aligned}
& \phi(p, \alpha) \equiv m \tilde{D}(p, \alpha)-q(p)=0 \\
& \Psi(p, \alpha) \equiv-\frac{m}{s^{\prime \prime}}-q^{\prime}(p)=0
\end{aligned}
$$

where $\mathrm{m}$ is defined by equation (19). Now note that $\phi \leq 0$ on the boundaries $p=P_{\min }$ and $\tilde{z}=1$. The first contention is obvious; the second follows from 
the fact that zero profits are made at $p=p_{\max }$. If $\tilde{z}(p, \alpha)=1$, the same demand is received as at the high price, but the price is lower. Therefore any loars $\phi(p, \alpha)=0$ can touch the boundary of the region in figure 3 only where $\alpha=1$. By assumption, there is some $\mathrm{p}$ such that $\operatorname{ac}\left[q\left(\mathrm{p}_{\max }\right) z\right]<\delta \mathrm{p}_{\max }-\mathrm{s}^{\prime}(z-1)$. Otherwise there would be a one-price equilibrium. Thus there is some $\mathrm{p}$ such that $\phi(p, 1)>0$. By continuity of $\phi$ then, a curve such as $\phi(p, \alpha)=0$ in figure 4 must exist.

But when $\alpha=1$, the dependence of demand $D\left(p ; \alpha, p^{\prime}\right)$ on $p^{\prime}$ is obviously irrelevant. If only the monopoly price is charged $D\left(p ; 1, p^{\prime}\right)=\tilde{D}(p, 1)=m z^{*}\left(p ; 1, p^{\prime}\right)$ independent of $p^{\prime}$. All buyers have no stocks. Thus $\Psi(p, 1)=m \frac{\partial \Phi}{\partial p}-q^{\prime}(p)=\frac{\partial \phi}{\partial p}$ (this is not true if $\alpha \neq 1$ ). Since $s$ is quadratic, and $q^{\prime \prime}>0, \frac{\partial \Psi}{\partial p}(p, 1)=-q^{\prime \prime}(p)<0$. Thus $\Psi\left(p_{1}, 1\right)>0$ at $p_{1}$ in figure 4 , where $\phi\left(p_{1}, 1\right)=0$ and $\Psi\left(p_{2}, 1\right)<0$ at $p_{2}$ $\left(p_{2}>p_{1}\right)$ where $\phi\left(p_{2}, 1\right)=0$, since $\Psi=0$ at the 1 ocal maximum of $\phi(p, 1)$ between $\mathrm{p}_{1}$ and $\mathrm{p}_{2}$. By continuity of $\Psi$, there must be some point on the curve $\phi(p, \alpha)=0$ where $\Psi(p, \alpha)=0$.

At such a point, profits are zero at the lowest price observed. By construction (of $\mathrm{m}$ ), they are zero at the high price $\mathrm{p}_{\max }$. The demand curve $\mathrm{mD}\left(\mathrm{p} ; \mathrm{a}, \mathrm{p}^{\prime}\right)$ is tangent to the average cost curve at $\mathrm{p}=\mathrm{p}^{\prime}$. All that remains to be shown is that no other price makes positive profit. But from equations (18) and (22)

$$
m \frac{\partial D}{\partial p}-q^{\prime}(p)=-\frac{m}{s^{\prime \prime}}-q^{\prime}(p)
$$

Therefore $\mathrm{mD}\left(\mathrm{p} ; \alpha, \mathrm{p}^{\prime}\right)-\mathrm{q}(\mathrm{p})$ is concave as a function of $\mathrm{p}$, and has a unique maximum at $p=p^{\prime}$. (Of course this curve is only defined for $p<p^{*}(1)$, but it has already been argued that no price between $\mathrm{p}^{*}(1)$ and $\mathrm{p}_{\max }$ could make a profit.)

It should be noted that the assumptions required were quite strong. If the total cost function is of the form $\mathrm{TC}=\mathrm{a}+\mathrm{bq}$, then the assumptions cannot hold. 10 It can be verified that if $\delta=.99, p_{\max }=10, s(x)=\frac{1}{2} x^{2}$, and 
$\mathrm{TC}=\frac{3}{2}+8 \mathrm{q}+\frac{\mathrm{q}^{2}}{2}$ for $\mathrm{q} \leq \sqrt{2}, \mathrm{TC}=9 \mathrm{q}+(9.5-9 \sqrt{2})$ for $\mathrm{q}>\sqrt{2}$, then $\mathrm{q}\left(\mathrm{p}_{\max }\right)=1$, and $\operatorname{ac}(1.2)=9.43<\delta \mathrm{p}_{\max }-s^{\prime}(.2)=9.9-.2=9.7$. But $\delta\left(\mathrm{p}_{\max }-\mathrm{s}^{\prime}(1)\right)=9=\mathrm{p}_{\min }$. This example required a very high discount factor, and a kink in the average cost curve. (Average cost is, by construction, continuous.)

However, the assumptions are by no means necessary for the result. They were only imposed to aviod complications with the jumps in the demand function. Figure 5 illustrates a possible two-price equilibrium when it is not true that $\mathrm{p}_{\min } \geq \delta \mathrm{p}_{\max }-\mathrm{s}^{\prime}(1)$. It must be true that $\Psi>0$ when $\mathrm{p}=\mathrm{p}_{\min }$ (since this just means the demand curve is steeper than the average cost curve). Hence, if there is a local maximum for $\phi(p, 1)$ at $p_{3}$ as in figure 5 , and the $\phi=0$ and $\Psi=0$ curves intersect, this intersection is a two-price equilibrium. (Note that the demand curve falls and gets steeper as $z^{*}$ rises, and so no profits can occur for lower prices.) But I cannot rule out a situation such as in figure 6. In this case there may be a two-price equilibrium at a jump in the demand curve (i.e., at $\mathrm{p}_{4}$ where $z^{*}=2$ ), or at some higher stockpile level, or an equilibrium with more than 2 prices. Section 7 immediately following provides a general proof of the existence of equilibrium; section 10 provides a numerical example of a two-price equilibrium (which does not satisfy assumption (B)).

\section{An Existence Proof}

In this section, a proof is provided of the existence of an equilibrium. It uses a fixed-point argument, and implies nothing about the number of prices in equilibrium. However it does not require the convexity assumption (B). Assumption (A) still must hold.

Let $F$ be an arbitrary distribution function for prices $\left(F(0)=0, F\left(p_{\max }\right)=1\right.$, F non-decreasing). Then the optimal stocks $z *(p)$ for this distribution can be calculated from (5) and (7) above. This $z^{*}$ function will be bounded above. 
In section 3 above it was shown $\mathrm{p}_{\max } / \mathrm{s}^{\prime}(0)$ was an upper bound. The distribution of customers $G()$ can then be calculated using (11) and (12). Then the aggregate demand $D$ can be defined by (10). Finally define ${ }^{11}$

$$
\widetilde{F}(p)=\int_{0}^{p} \frac{D(\pi)}{q(\pi)} d F(\pi)
$$

and

$$
\begin{array}{r}
\tilde{F}(p)=\tilde{\widetilde{F}}(p) / \tilde{\mathrm{F}}\left(\mathrm{p}_{\max }\right) \\
\mathrm{m}=1 / \tilde{\widetilde{F}}\left(\mathrm{p}_{\max }\right)
\end{array}
$$

Since $F$ is a distribution function, and $D$ is a bounded non-increasing function, $\tilde{\tilde{F}}$ is well-defined, and $\lim \tilde{\tilde{F}}<\infty$. This implies $\tilde{F}$ is itself a distribution function. By construction $\tilde{\mathrm{F}}\left(\mathrm{P}_{\max }\right)=1$. Also, $\tilde{\mathrm{F}}$ is continuous as a function of F. (That is the map Ffrom the space of distribution functions on $\left[0, \mathrm{p}_{\max }\right]$ into itself is continuous, where $\widetilde{J}_{\mathcal{F}}(\mathrm{F})=\tilde{\mathrm{F}}$.)

The space of distribution functions on $\left[0, \mathrm{p}_{\max }\right]$ is a Banach space, and thus a fixed point space. ${ }^{12}$ Hence there exist $m, F$ such that

$$
F(p)=\int_{0}^{p} \frac{m D(\pi)}{q(\pi)} d F(\pi)
$$

This distribution must be shown to be an equilibrium.

Suppose $\frac{m D(p)}{q(p)}>1$. By continuity it must be positive over some interva1 $\left(\mathrm{p}^{\prime}, \mathrm{p}^{\prime \prime}\right)$. But then $\mathrm{F}\left(\mathrm{p}^{\prime \prime}\right)-\mathrm{F}\left(\mathrm{p}^{\prime}\right)>\int_{\mathrm{p}^{\prime}}^{\mathrm{p}^{\prime \prime}} \mathrm{dF}(\pi)$, a contradiction. Similarly if $\mathrm{F}\left(\mathrm{p}^{\prime}\right)>\mathrm{F}\left(\mathrm{p}^{\prime \prime}\right)$ and $\frac{\mathrm{mD}(\mathrm{p})}{\mathrm{q}(\mathrm{p})}<1$ in $\left[\mathrm{p}^{\prime}, \mathrm{p}^{\prime \prime}\right]$ then $\mathrm{I}$ can find an $\Sigma>0$ such that $\frac{m D(p)}{q(p)}<1-\Sigma$ in $\left[p^{\prime}, p^{\prime \prime}\right]$. Thus $F\left(p^{\prime}\right)-F\left(p^{\prime \prime}\right)=\int_{p^{\prime}}^{p^{\prime \prime}} \frac{m D(p)}{q(p)} d F(p)<(1-\Sigma) \int_{p^{\prime}}^{p^{\prime \prime}} d F(p)$ $<F\left(p^{*}\right)-F\left(p^{\prime \prime}\right)$. Thus if $F\left(p^{\prime}\right)>F^{\prime}\left(p^{\prime \prime}\right)$ there must be some $p \in\left[p^{\prime}, p^{\prime \prime}\right]$ where $m D(p)=q(p)$. Hence if $F$ jumps at $p$, there must be a succession of $p^{\prime}<p$, $\mathrm{p}^{\prime \prime}-\mathrm{p}$ with $\mathrm{p}^{\prime}, \mathrm{p}^{\prime \prime} \rightarrow \mathrm{p}$ such that $\mathrm{F}\left(\mathrm{p}^{\prime}\right)<\mathrm{F}\left(\mathrm{p}^{\prime \prime}\right)$, so that the above argument shows $\mathrm{mD}(\mathrm{p})=\mathrm{q}(\mathrm{p})$ in the limit. Also if $\mathrm{F}$ is differentiable at $\mathrm{p}$ and $\mathrm{F}^{\prime}>0$, this argument shows $\mathrm{mD}(\mathrm{p})=\mathrm{q}(\mathrm{p})$. Therefore $I$ have shown the existence of an equilibrium price distribution. 
This equilibrium proof will carry over, mutatis mutandis, to a situation with different reservation prices, or different demands among buyers. It is required that prices be bounded above, as must purchases of all buyers. If reservation prices $\mathrm{p}_{\max }$ can be bounded above, and storage costs $s^{\prime}(0)$ bounded below, such a requirement is satisfied. Then an equilibrium will exist when buyers vary by reservation price, discount factor, storage costs, and/or length of the buying interval.

\section{Justifying the Assumptions}

At this stage, a few words should be said concerning the veracity and applicability of the model. Perhaps its least palatable aspect is the random assignment of buyers to sellers. Why can buyers work out the intricacies of the intertemporal stochastic optimization, and not remember who the cheap sellers are? First, note that the optimization turns out in many cases not to be too intricate. One merely has to know what the low price is, what the probability of encountering this price is, and how much one should stock upon encountering this seller. In essence the model requires only that buyers know a low price when they see it; this may be easier that remembering the identity of low-priced sellers.

It also may not be the case that sellers maintain the same price. If one seller were consistently charging the low price, search by buyers might be justified. Clearly the costs of search must be weighed against the expected value of the benefits. For a given price differential, search may be justified if stores are expected to keep the same prices in future, but not justified for this period's benefits alone (i.e., $\hat{p}-p_{10 w}<c$, but $E[V(z, p)]-\frac{p_{10 w}}{1-\delta}>c$, where $c$ is search cost and $\mathrm{p}_{10 \mathrm{w}}$ the low observed price). The possibility of 
storage lowers the gains from search. It can be shown that $E[V(0, p)]<\frac{\hat{p}}{1-\delta}$, or the expected costs of future purchases (given that one has nothing on hand) are less than the capitalized expected price. ${ }^{13}$

If search costs are introduced to the stockpiling model, the results may be altered. In particular, a two-price equilibrium will be sustainable precisely when $E[V(0, p)]<\frac{\mathrm{P}_{10 \mathrm{w}}}{1-\delta}+\mathrm{c}$, where $\mathrm{c}$ are search costs. If this condition does not hold, then some other multi-price equilibrium exists. A possible three-price equilibrium is shown in figure 7. Prices must be such that $E\left[V(0, p)=\frac{p_{2}}{1-\delta}+c\right.$ so that buyers with no stocks are on the margin of searching. The demand curve shown is for non-searchers. The horizontal distance between the demand curve and the average cost curve at $p_{2}$ is the number of searchers. Sellers at $\mathrm{p}_{\max }$ sell only to non-searchers with low $(<1)$ stocks on hand; sellers at $p_{1}$ sell to non-searchers (and sell $z *(p)-z$ units to them); sellers at $p_{2}$ sell 1 unit to each searcher, and $z^{*}(p)-z$ units to non-searchers.

Nonetheless, implicit above is that people who choose to search do so once, and then remember the seller at which they encountered the lowest price. Yet buyers who accidentally stumble on low-prices sellers do not remember. This peculiarity holds in all search models in which individual sellers do not vary prices. It suggests that one of the following 3 cases must happen in any price-dispersion model involving search

(i) individual sellers' prices vary over time (although the overall distribution is stationary); hence search must be undertaken in each period

(ii) individual sellers' prices do not vary; but all buyers are forgetful so that search must be undertaken in each period 
(iii) individual sellers' prices do not vary; those buyers who search remember the low price stores, and must only search once, but those who accidentally encounter a low-price seller are forgetful. What the above taxonomy suggests is that my assumptions about buyers' knowledge are no stronger than those required by search models. The stockpiling model requires buyers to regard next period's price as a drawing from a known distribution. But in search models either next period's price (at any individual seller) actually is random (case (i)), or some (case (iii) or all (case (ii)) buyers gain no information from previous experience.

I find case (i) to be the most plausible situation--for both search and stockpiling models. It certainly is the only case compatible with "sales" noted by Varian. In addition, price variability seems the only rational strategy if all buyers do remember. Any store consistently charging any price above the minimum would lose all customers eventually. Hence all stores charging the same price and all stores randomizing seem to be the two possibilities if buyers can remember.

Thus the notion that buyers regard next period's price as a random variable is not unreasonable. But it should be pointed out that $I$ also have assumed that each seller's distribution of buyers is a microcosm of the economy's. This assumption is not tenable if buyers actually stay with the same seller. Then a seller who had charged $\mathrm{p}_{\max }$ last period would have buyers all of whose stocks were zero this period (if $z^{*}\left(p_{10 w}<2\right)$. Even if the seller did not take advantage of this information, his actual demand would be higher than that defined by equation (10). The zeromprofit condition would then be that on average profits were zero at prices $p_{\max }$ and $p_{10 w}$, or $\int a c\left[m\left(z^{*}(p)-z\right)\right] d G(z)=p$. In general this condition is not the same as making zero profits with an average 
buyer distribution, $\operatorname{ac}\left[\mathrm{m} \int\left(z^{*}(\mathrm{p})-z\right) \mathrm{dG}(z)\right]=\mathrm{p}$. The two conditions are equivalent only if the average cost is 1 inear. ${ }^{14}$ Therefore the formal model presented does require buyers actually to choose a different seller each period, unless the average cost function is linear over the relevant range.

An alternative rationale for using the model presented here (or something like it) and having buyers returning to the same sellers is to vary the purchase period. Suppose buyers buy once a "week", but the date within the week when they buy is random. Sellers change prices every "day". Then the buyers entering the store each day will include people whose previous week's purchases were on different days. That is, any day's customers will include $\frac{1}{7}$ of those who bought the previous Sunday plus $\frac{1}{7}$ of those who bought the previous Monday and so on. If the number of "days" in a "week" is large enough, each seller will regard his clientele as a microcosm of the aggregate distribution $G$.

\section{Comparative Statics with a Linear Version}

To consider some implications of two-price equilibria, comparative static properties of a simple linear example will be derived. Both sellers' total cost functions and buyers' storage cost functions are assumed linear. Let $s$ be the cost of storing one unit for one period $(s>0)$. Let each firm's total cost function be $c_{0}+c_{1} q\left(c_{0}>0, c_{1}>0\right)$. The 1inearity of storage implies demand will be a step function. So will the $z^{*}$ function. Buyers will be indifferent among any of the stocks along the horizontal portions of the $z$ * curve. Therefore it must be assumed that all buyers actually choose the maximal stock among which they are indifferent. In the example illustrated in figure 8 , buyers will be willing to hold any stock between 1 and 2 at a price of 6 , and I assume they choose to hold 2. 
Given the 1inearity, any two-price equilibrium can be described by 3 equations, which determine the endogenous variables $\alpha$ (the proportion of sellers charging the monopoly price), $\mathrm{p}$ (the low price) and $\mathrm{m}$ (the buyer-seller ratio). If the optimal stocks are 2 (the maximal values of $z$ in the horizontal stretches of the $z^{*}(p)$ curve are at integer values), then the equation for the optimal stock (equation (5), or (21)) is

$$
(1-\delta(1-\alpha)) p=\alpha \delta p_{\max }-s
$$

Zero profit for the high-priced sellers implies

$$
\alpha \mathrm{m} \mathrm{p}_{\max }=c_{0}+\alpha c_{1} \mathrm{~m}
$$

since the left-hand side is total revenue (only the buyers who have no stocks will buy at a price of $\mathrm{p}_{\max }$, since $z *(\mathrm{p})=2$ ), and the right-hand side is total cost. Zero profit for the 10w-priced store requires

$$
(2 \alpha+(1-\alpha)) m p=c_{0}+(2 \alpha+(1-\alpha)) c_{1} m
$$

The example illustrated in figure 8 involves the following data

$$
\mathrm{p}_{\max }=12, \mathrm{~s}=.75, \mathrm{c}_{\mathrm{o}}=45, \mathrm{c}_{1}=3, \delta=.75
$$

These data yield an equilibrium with

$$
\alpha=.5, p=6, m=10, z *(6)=[1,2]
$$

The expected cost function $\mathrm{V}$ can be calculated explicitly in this example.

\begin{tabular}{|c|c|c|}
\hline & $0 \leq p \leq 6$ & $6 \leq \mathrm{p} \leq 12$ \\
\hline $\begin{array}{l}0 \leq z \leq 1 \\
1 \leq z \leq 2\end{array}$ & $\begin{array}{l}21+2 p-p z \\
21+2 p-p z\end{array}$ & $\begin{array}{c}27+p-p z \\
33-6 z\end{array}$ \\
\hline
\end{tabular}
$v_{1}(z, p)=-p$ in regions 1 and 2 , and $v_{1}(z, p)=-p^{*}(z)=-6$ for $1<z<2$ and $(z, p)$ in region 3. Also equation 1 shows $v_{2}=z^{*}-z$ in region $1, v_{2}=1-z$ in region $2, V_{2}=0$ in region 3 . It then can be seen that $V$ satisfies the following formula in the example 
The cost function is continuous, but has kinks along the $z^{*}$ curve. Note that $\mathrm{E}[\mathrm{V}(0, \mathrm{p})]=\alpha \mathrm{V}\left(0, \mathrm{P}_{\max }\right)+(1-\alpha) \mathrm{V}(0, \mathrm{p})=36=\frac{\hat{\mathrm{p}}}{1-\delta}$. A buyer with no stocks on hand is made no better off by being able to store. This result is due to the linearity; encountering a price of 6 , the buyer is indifferent among all levels of stockpiling less than or equal to 1 . Also $E[V(1, p)]=27=\frac{\delta \hat{p}}{1-\delta}$, so that storage does not help a buyer with stocks on hand (who otherwise would buy nothing this period and exactly 1 unit in every subsequent period). However, if nobody stored, then the observed price distribution would differ. Only the monopoly price would be observed. Thus buyers choosing to store (when they are actually indifferent) causes an external benefit. ${ }^{15}$ The average present value of this benefit is 16.5 , since expected costs would be $\frac{P_{\max }}{1-\delta}=48$ if there were no storage, and are $\alpha(27)+(1-\alpha)(36)=31.5$ when there is storage. Of course if the storage function $s($ ) were non-linear, buyers would strictly prefer to store.

More genera11y, in any linear, two-price equilibrium it can be shown that

$$
\left[\begin{array}{l}
E(V(0, \cdot)) \\
E(V(1, \cdot))
\end{array}\right]=\frac{1}{1-\delta}\left[\begin{array}{l}
\hat{p} \\
\delta \hat{p}
\end{array}\right]
$$

If equation (25) is solved for $\mathrm{m}$, then equations (24) and (26) can be written as

$$
\begin{aligned}
{\left[\begin{array}{lr}
\mathrm{P}_{\max }-\mathrm{p} & -(1+\alpha) \\
\delta\left(\mathrm{p}_{\max }-\mathrm{p}\right) & -(1-\delta(1-\alpha))
\end{array}\right]\left[\begin{array}{l}
\mathrm{d} \alpha \\
\mathrm{dp}
\end{array}\right] } & =\left[\begin{array}{c}
-\mathrm{1} \\
0
\end{array}\right] \mathrm{dc} c_{1}+\left[\begin{array}{c}
-\alpha \\
-\alpha \delta
\end{array}\right] \mathrm{dp} \mathrm{max}_{\max } \\
+ & {\left[\begin{array}{l}
0 \\
-\alpha \mathrm{p}_{\max }-(1-\alpha) \mathrm{p}
\end{array}\right] \mathrm{d} \delta+\left[\begin{array}{l}
0 \\
1
\end{array}\right] \mathrm{ds} }
\end{aligned}
$$

which can be used to obtain the desired comparative-static results. 
The first, and perhaps the most striking, result occurs as the reservation price varies. From (28), and the definition of $\hat{p}$

$$
\frac{\partial p}{\partial p_{\max }}=0, \frac{\partial \alpha}{\partial p_{\max }}=\frac{\alpha}{p_{\max }-p}<0, \frac{\partial \hat{p}}{\partial p_{\max }}=0
$$

An increase in the reservation price affects neither the low price, nor the average price. It also can be seen from equation (24) that the number of sellers falls as the reservation price rises. From (29) and (24)

$$
m-\frac{p_{\max }-c_{1}}{p_{\max }-p} m+\left(p_{\max }-c_{1}\right) \frac{\partial m}{\partial p_{\max }}=0
$$

Since $c_{1}-p$ if low-priced stores are to break even, $\frac{\partial \mathrm{m}}{\partial \mathrm{p}_{\max }}>0$. Although the direct effect of a rise in the reservation price is to raise profits (and thus induce entry), the changes induced in storage behavior eventually lead to exit in the industry, particularly among high-priced stores.

Although the average price observed is unchanged, total costs paid by buyers has fallen. From (27), the change in the reservation price has left expected costs unchanged for any initial stock level. But since $\alpha$ has fallen, more buyers will be observed with high stocks. Average per capita costs have fallen by $\alpha \cdot \frac{\hat{p}}{p_{\max }-p}$ per unit rise in the reservation price. For instance, a rise in the reservation price from 12 to 15 lowers the average annual costs (purchase plus storage) of buyers from 7.875 to 7.5 .

This "perverse" result depends on the specific functional forms. But Diamond and Rothschild (1978, exercise, p. 488) have noted that an increase in the reservation price will increase the proportion of low-priced stores in the Salop-Stiglitz (1977) model. Here the result can be given a welfare implication. Of course no mention has been made of the utility function underlying the demand function. But suppose the reason for the reservation price property is the existence of a perfect substitute (which cannot be stored) 
at a price of $\mathrm{p}_{\max }$. Then a rise in the price of the substitute unambiguously makes buyers better off. An alternative way of viewing this result is to note that expected costs per buyer per period must equal $\frac{c_{0}}{m}+c_{1}+(1-\alpha) s$. This expression combines buyers' storage costs and sellers' costs. No matter what happens, on average 1 unit per buyer per period is bought, so the marginal cost of these sales is $c_{1}$. The fixed cost per buyer is clearly $\frac{c_{0}}{m}$. And if those who visit 1ow-priced sellers store 1 unit, $(1-\alpha)$ s per buyer is devoted to storage. It can be shown that $\alpha \mathrm{E}[\mathrm{V}(0, \cdot)]+(1-\alpha)[\mathrm{V}(1, \cdot)]=\frac{1}{1-\delta}\left[\frac{\mathrm{c}_{0}}{\mathrm{~m}}+\mathrm{c}_{1}+(1-\alpha) \mathrm{s}\right]^{16}$ When the reservation price increases, more storage activity is undertaken. But these added costs are more than balanced by the economies of scale caused by "larger stores" (the increase in $\mathrm{m}$ ).

The other derivatives are less surprising. If the marginal cost $c_{1}$ varies

$$
\frac{\partial \alpha}{\partial c_{1}}=\frac{1-\delta(1-\alpha)}{\left(p_{\max }-p\right)(2 \delta-1)} ; \frac{\partial p}{\partial c_{1}}=\frac{\delta}{2 \delta-1} ; \frac{\partial \hat{p}}{\partial c_{1}}=\frac{1}{2 \delta-1}
$$

If the purchase period is reasonably short so that $\delta>.5$, increases in marginal cost raise both the lower price, and the proportion of sellers charging the higher price. The scale of sellers decreases. (Since each high-priced seller gets $\alpha \mathrm{m}$ sales, and $\alpha$ has fallen, m must rise to maintain the zero profit condition in the face of higher marginal costs.) The increase in average annual cost is (from equation (27)), $\frac{\alpha+\delta(1-\alpha)}{2 \delta-1}+\frac{\hat{p}(1-\delta)}{p_{\max }-p} \frac{1-\delta(1-\alpha)}{2 \delta-1}$. For $\delta>\frac{1}{2}$, this increase exceeds 1 . The overall effect of increases in marginal cost is greater than the "direct" effect of 1 , since storage costs have increased as has the number of sellers. 
If the discount factor $\delta$ changes

$$
\begin{aligned}
& \frac{\partial \alpha}{\partial \delta}=-\frac{(1+\alpha)}{\left(p_{\max }-p\right)} \cdot \frac{\alpha\left(p_{\max }-p\right)+p}{2 \delta-1} \\
& \frac{\partial p}{\partial \delta}=-\frac{\left(\alpha\left(p_{\max }-p\right)+p\right)}{2 \delta-1} \quad \frac{\partial \hat{p}}{\partial \delta}=-\frac{2}{2 \delta-1}\left(\alpha\left(p_{\max }-p\right)+p\right)
\end{aligned}
$$

Since $\alpha$ and $\hat{\mathrm{p}}$ fall if $\delta$ rises, so must annual expected costs. Worrying more about the future makes storage more attractive, and ultimately pays off in lower annual costs.

If storage costs increase, so do prices.

$$
\frac{\partial \alpha}{\partial s}=\frac{1+\alpha}{\left(p_{\max }-p\right)(2 \delta-1)} \quad \frac{\partial p}{\partial s}=\frac{1}{2 \delta-1} \quad \frac{\partial \hat{p}}{\partial s}=\frac{2}{2 \delta-1}
$$

The overall effect on expected costs is $(1-\alpha)+\frac{P_{\max }-s}{P_{\max }-p} \frac{(1+\alpha)}{(2 \delta-1)}$ which exceeds the "direct" effect of $1-\alpha$ if $\mathrm{p}_{\max }>\mathrm{s}$, which must be the case. The amount of storage has declined $\left(\frac{\partial \alpha}{\partial s}>0\right)$, but this effect is more than balanced by the increased fixed costs. (Equation (25) indicates m must have decreased.)

Finally, an increase in fixed costs $c_{0}$ has no effect at all on buyers' costs. Entry barriers are irrelevant. Of course this result may be of dubious value to anti-trust authorities; sellers' monopoly power does not depend at all here on the number of sellers. What occurs when $c_{0}$ rises is that the buyer-seller ratio $\mathrm{m}$ increases proportionately. The term $\mathrm{c}_{\mathrm{o}}$ does not appear explicitly in equation (28), and one can see that multiplying $c_{0}$ and $m$ by the same constant will not alter equilibrium conditions (24)-(26).

\section{An Example of a Two-Price Equilibrium}

The numerical example used for figure 8 can be used to construct an example of a two-price equilibrium where storage is quadratic, by a slight modification. Again let

$$
\delta=.75, \mathrm{TC}=45+3 \mathrm{q}, \mathrm{p}_{\max }=12
$$


but now let storage costs $s()$ be defined by

$$
s(x)=\frac{1}{4}\left(x^{2}+x\right)
$$

An equilibrium will still exist with $\alpha=\frac{1}{2}, m=10, p=6, \tilde{z}(p, \alpha)=2$, since $s^{\prime}(1)=.75$, just as in the linear example. Here the demand curve is linear between jumps. Since $D(p)=\alpha z^{*}(p)+(1-\alpha)\left(z^{*}(p)-1\right)$, and $p+s^{\prime}\left(z^{*}-1\right)=\delta \hat{p}$, demand has the equation

$$
\operatorname{mD}(\mathrm{p})=135-20 \mathrm{p} \quad \text { for } 1<z^{*}<2
$$

The $p$ for. which $z^{*}(p)=1$ is 6.5 (here $\left.p+s^{\prime}(0)=p=\delta \hat{p}\right)$. At $m D=15, p=6$, the demand curve drops to a level where $p+s^{\prime}(1)=\delta\left[(1-\alpha) 6+\alpha p^{*}(1)\right]$, (from equation (7)). This level is $p=3 \frac{27}{32}$. Repeated application of equation (7) yields figure 9, which shows a two-price equilibrium. Note that assumption B of section 6 does not hold, since that assumption implied equilibrium stocks strictly less than 2. Thus such a strong assumption is not needed for the existence of a two-price equilibrium

\section{Summary}

The main purpose of this paper is to explain equilibrium price dispersion by the possibility of buyers purchasing for future use when "bargains" are encountered. This possibility provides an alternative explanation to search for such dispersion. It also explains why rational buyers may stock up at sales, which search models do not. Also, the possibility of two-price equilibria in this model explain the phenomenon noted by Varian (1980), that one seldom observes prices between the high "regular" price and the low "sale" price. of course, both search and stockpiling occur simultaneously. This model ignores search only for needed analytic tractability. Like search, individual buyers' 
stockpiling exerts a positive externality on other buyers. Unlike search, stockpiling cannot eliminate the possibility of encountering a seller charging the monopoly price. And, like many models with imperfect information, the stockpiling model yields somewhat different comparative static results from comventional analysis. 
${ }^{1}$ For example, Salop and Stiglitz (1977), Varian (1980), Bagnoli (1981), Butters (1977).

2 In particular, I hope to modify this model to examine the effects of commodity stabilization schemes, an application helpfully suggested by James Brander in a workshop at Queen's.

${ }^{3}$ Such as those cited in footnote 1.

${ }^{4}$ For brevity, this dependence on the perceived distribution will be suppressed in the notation, except where absolutely necessary, as in Section 6 .

$$
\begin{aligned}
& 5_{\text {If }}(z, p) \text { is in region } 1 \\
& v_{1}=s^{\prime}(x+z-1)+\delta E\left[V_{1}(x+z-1, \cdot)\right]+\frac{\partial x}{\partial z}\left[p+s^{\prime}(x+z-1)+\delta E\left[V_{1}(x+z-1, \cdot)\right]\right]
\end{aligned}
$$

from (2) this equals -p.

If $(z, p)$ is in region $2, x=1-z$, so $V=p(1-z)+\delta E[V(0, \cdot)]$.

${ }^{6}$ If the storage cost function $s$ is linear, $2 *$ will not be uniquely defined. The buyer will be indifferent among all purchases $x$ where $x+z \in z *(p)$.

7 The function $G(z)$ is meant to represent the proportion of buyers holding stocks less than or equal to $z$. So $\lim _{z \rightarrow \infty} G(z)=1$. The total number $P$ of buyers does not play any role in the analysis. As will be seen, what is important is $\mathrm{m}$, the ratio of buyers to sellers. I do require that $\mathrm{P} / \mathrm{m}$ be large enough for sellers to be able to disregard the effects on aggregate distributions of their own actions.

${ }^{8}$ This requires some modification if buyers vary in their reservation price. If a seller is known to charge the highest price, the only buyers purchasing will be those with inadequate stocks for current consumption, and they will purchase only what is necessary. If individuals differ, the 
highest-priced seller may charge a different price than a monopolist in a world with no storage. That is because the proportion of buyers who have inadequate stocks may vary among different types of buyers. But the pricing rule of such a seller will be a simple monopoly solution, in which future storage need not be considered.

${ }^{9}$ If the average cost curve is U-shaped, no great difficulties arise. Simply define $q(p)$ as the minimal level of $q$ for which ac $(q)=p$.

${ }^{10}$ Since $s$ is quadratic, then $\delta p_{\max }-s^{\prime}(z-1)$ is a straight line. Let its equation be $c-d(z-1)$. Profits are negative at $z *=1$, so (note

$$
\begin{array}{ll}
\left.q\left(p_{\max }\right)=m\right), \\
a c(m)=b+\frac{a}{m}>c \\
\text { If } & p_{\min } \equiv b>c-d \\
\text { then } & b+\frac{a}{m z}=\frac{b}{z}+\frac{a}{m z}+b\left(1-\frac{1}{z}\right)>\frac{c}{z}+(c-d)\left(1-\frac{1}{z}\right)=c-d\left(\frac{z-1}{z}\right)>c-d(z-1)
\end{array}
$$

So that ac $(\mathrm{mz})>6 \mathrm{p}_{\max }-s^{\prime}(z-1)$ for $1<z<2$

${ }^{11}$ Note as sumption $(A)$, that $q\left(p_{\max }\right)>0$, means that $\widetilde{F}^{\prime}$ will be well defined.

${ }^{12}$ This is Schauder's fixed point theorem. See Simmons (1963), p. 338.

$$
\begin{array}{r}
{ }^{13} \text { If } \mathrm{p}>\mathrm{p} *(1) \mathrm{V}(0, \mathrm{p})=\mathrm{p}+\delta \mathrm{E}[\mathrm{V}(0, \cdot)] \\
\text { If } \mathrm{p}<\mathrm{p} *(1) \mathrm{V}(0, \mathrm{p})<\mathrm{p}+\delta \mathrm{E}[\mathrm{V}(0, \cdot)]
\end{array}
$$

Integrating over all $\mathrm{p}$ yields the result.

${ }^{14}$ In both cases, the integration should be only over these $z$ with $z \leq z *(p)$.

${ }^{15}$ Presumably, buyers would be better off if they all stored more than was individually optimal, because of this externality. 
${ }^{16}$ From $(27), \alpha E[V(0, \cdot)]+(1-\alpha) E[V(1, \cdot)]=\frac{1}{1-\delta}(\alpha+(1-\alpha) \delta) \hat{p} . \quad$ From $(24)$, $\mathbf{p}=\delta \hat{\mathrm{p}}-\mathbf{s}$, so that $\frac{1}{1-\delta}(\alpha+(1-\alpha) \delta) \hat{\mathrm{p}}=\frac{1}{1-\delta}(\alpha \hat{\mathrm{p}}+(1-\alpha) \mathrm{p}+(1-\alpha) s)=$ $\frac{1}{1-\delta}\left(\alpha^{2} \mathrm{p}_{\max }+\mathrm{p}[(1-\alpha)(1+\alpha)]-(1-\alpha) \mathrm{s}\right)$. From $(25)$ and $(26)$ this equals $\left[c_{1}+\frac{c}{m}+(1-\alpha) s\right] \frac{1}{1-\delta}$. 


\section{$\underline{\text { References }}$}

Bagnoli, M. (1981): "Equilibrium with Uninformed Consumers," unpublished.

Butters, G. (1977): "Equilibrium Distributions of Sales and Advertising Prices," Review of Economic Studies 44, 3, Oct. 1977.

Diamond, P. and M. Rothschild (eds.) (1978): Uncertainty in Economics [New York: Academic Press, 1978].

Reinganum, J. (1979): "A Simple Model of Equilibrium Price Dispersion," Journal of Political Economy 87, 4, August 1979.

Salop, S. and J. Stiglitz (1977): "Bargains and Ripoffs," Review of Economic Studies 44, 3, Oct. 1977.

Simmons, G. (1963): Introduction to Topology and Modern Analysis

[New York: McGraw-Hil1 Publishing Co., 1963].

Varcan, H. (1980): "A Model of Sales," American Economic Review 70, 4, Sept. 1980. 

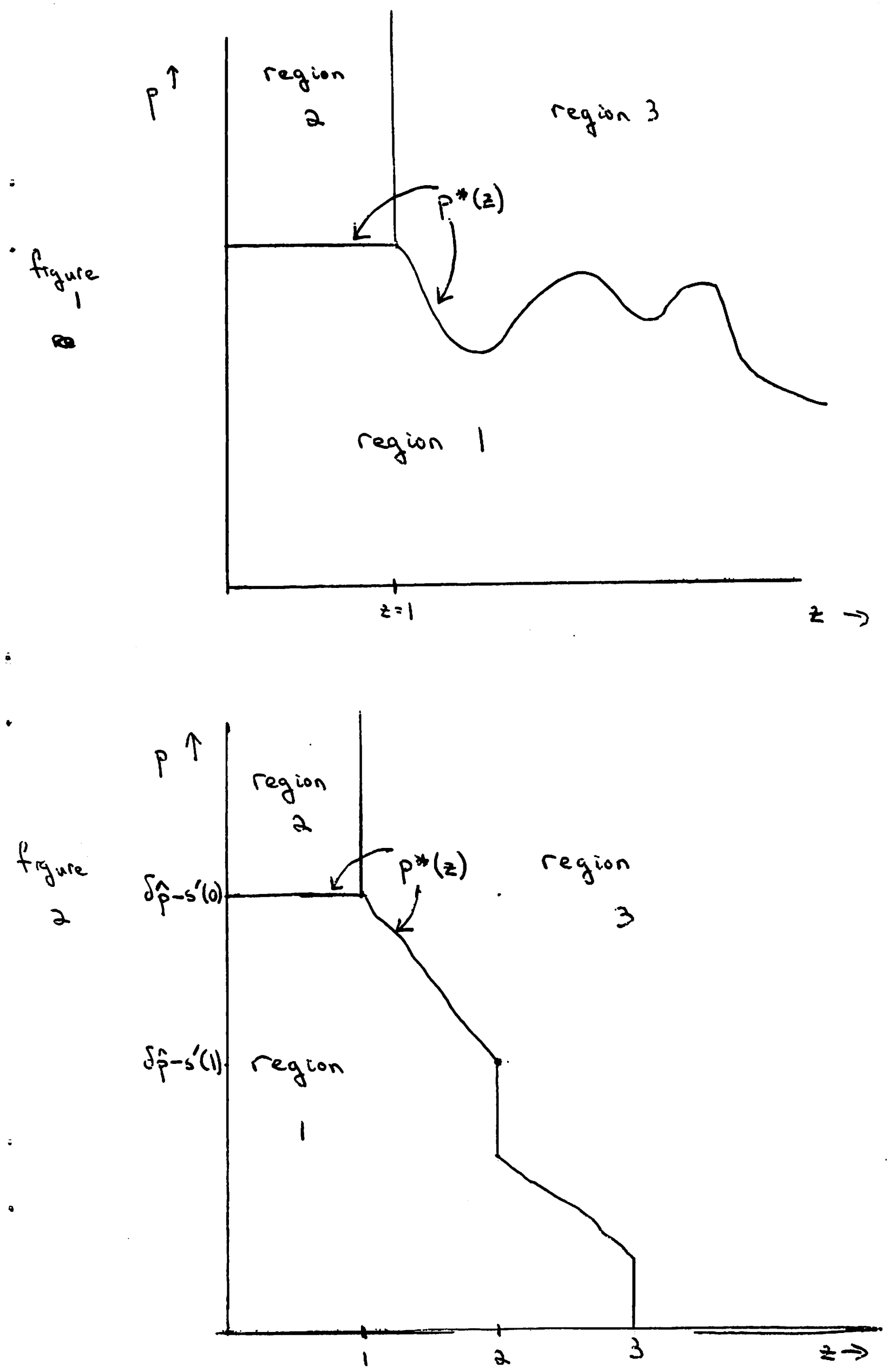

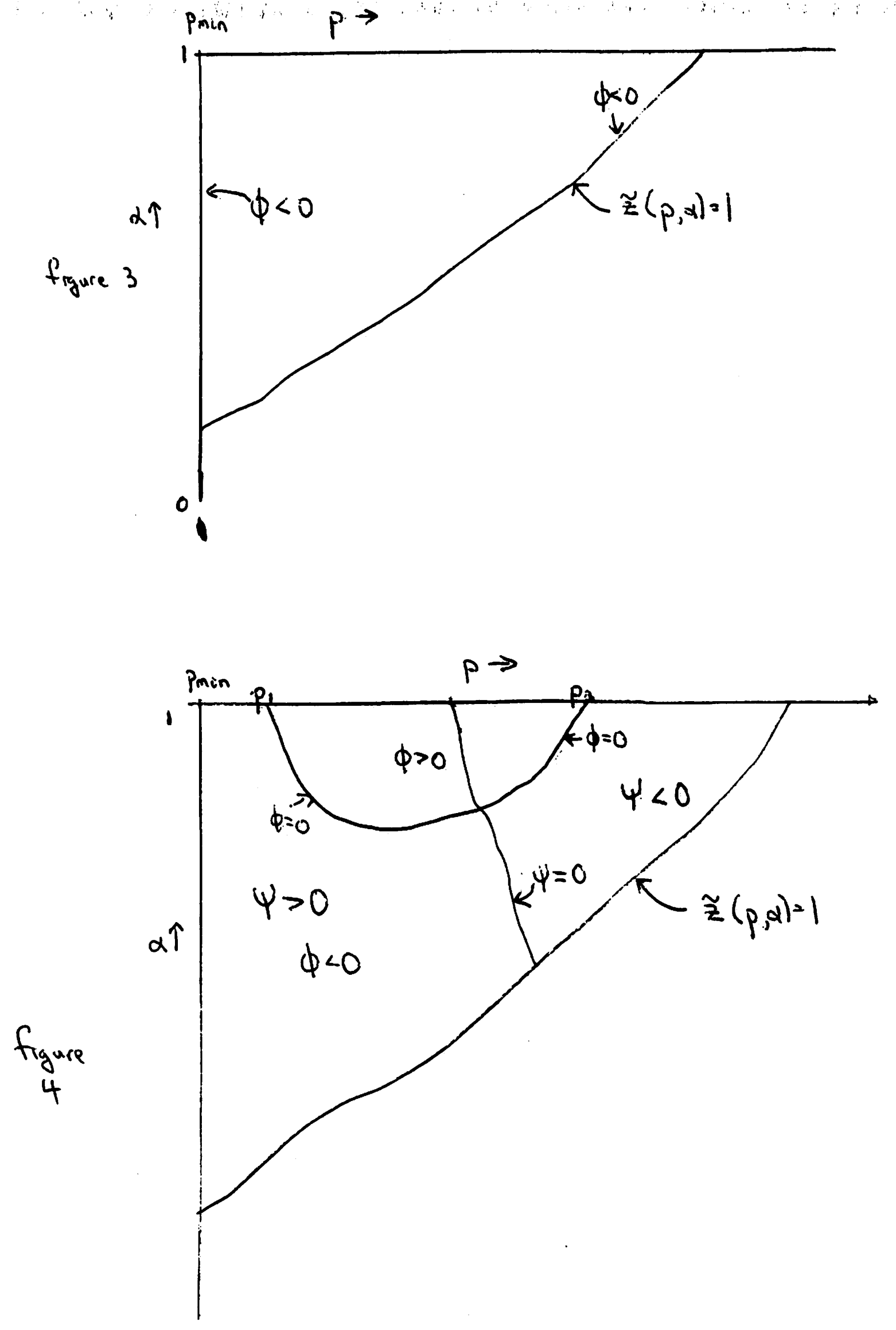

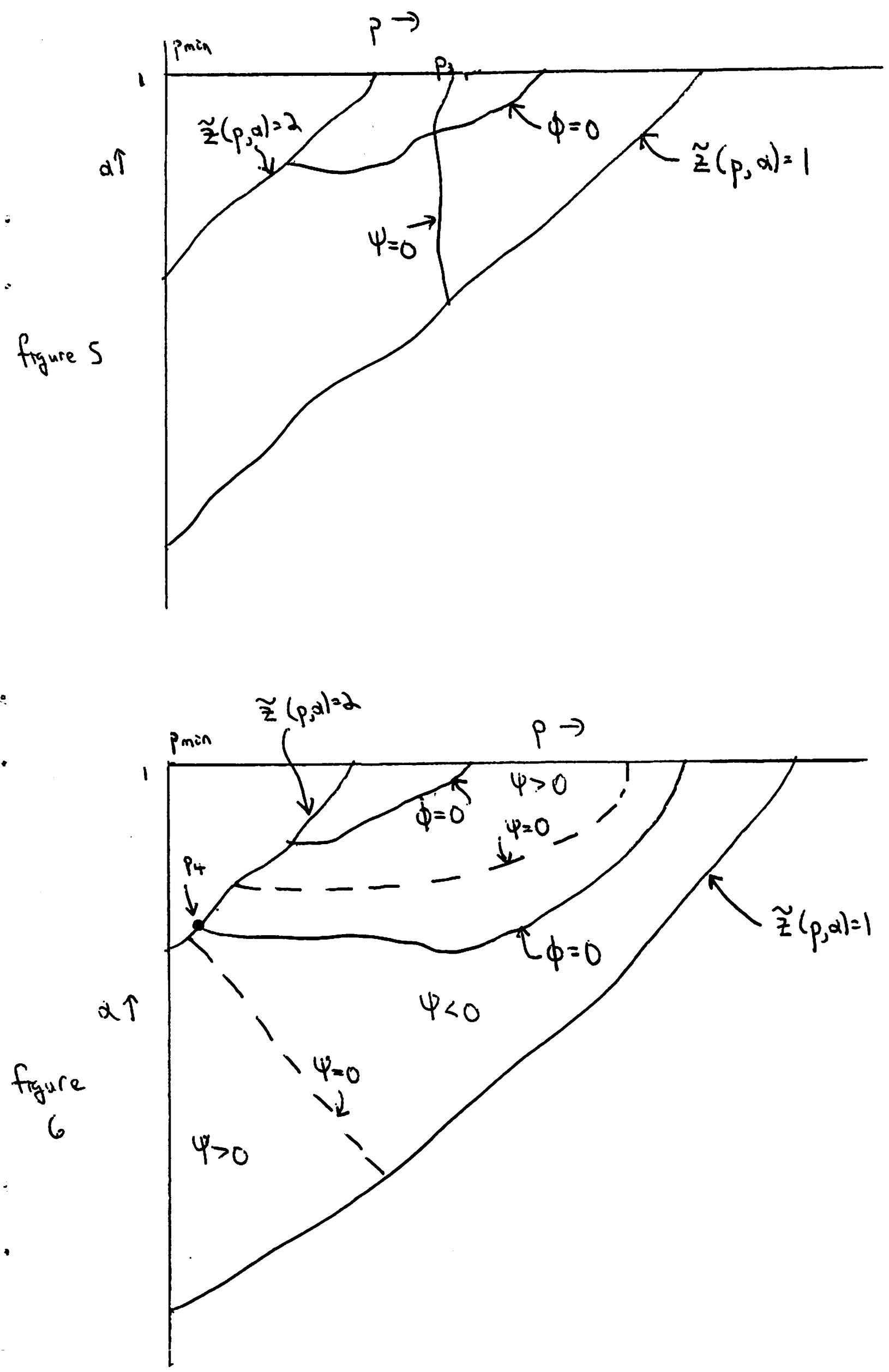


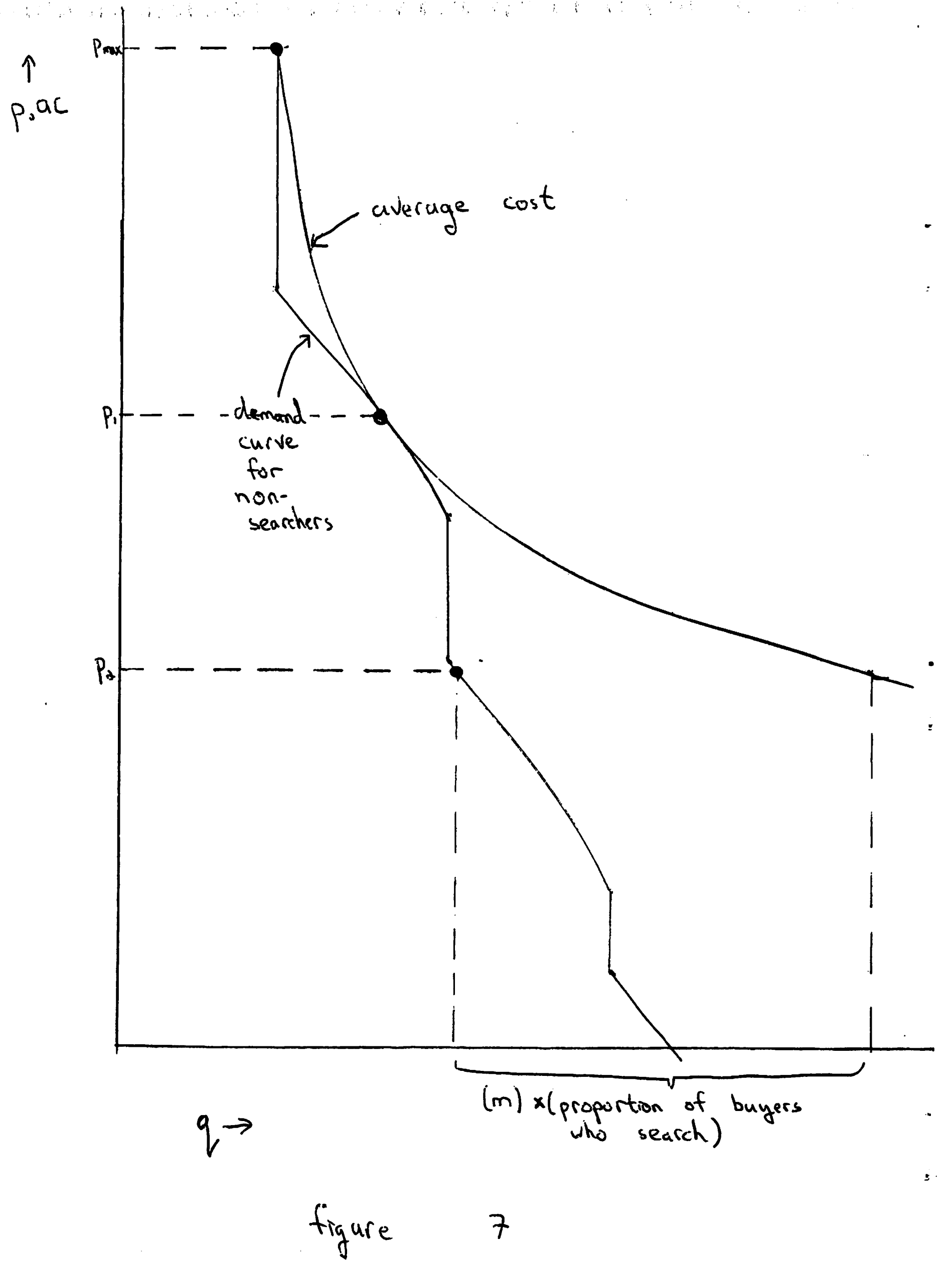




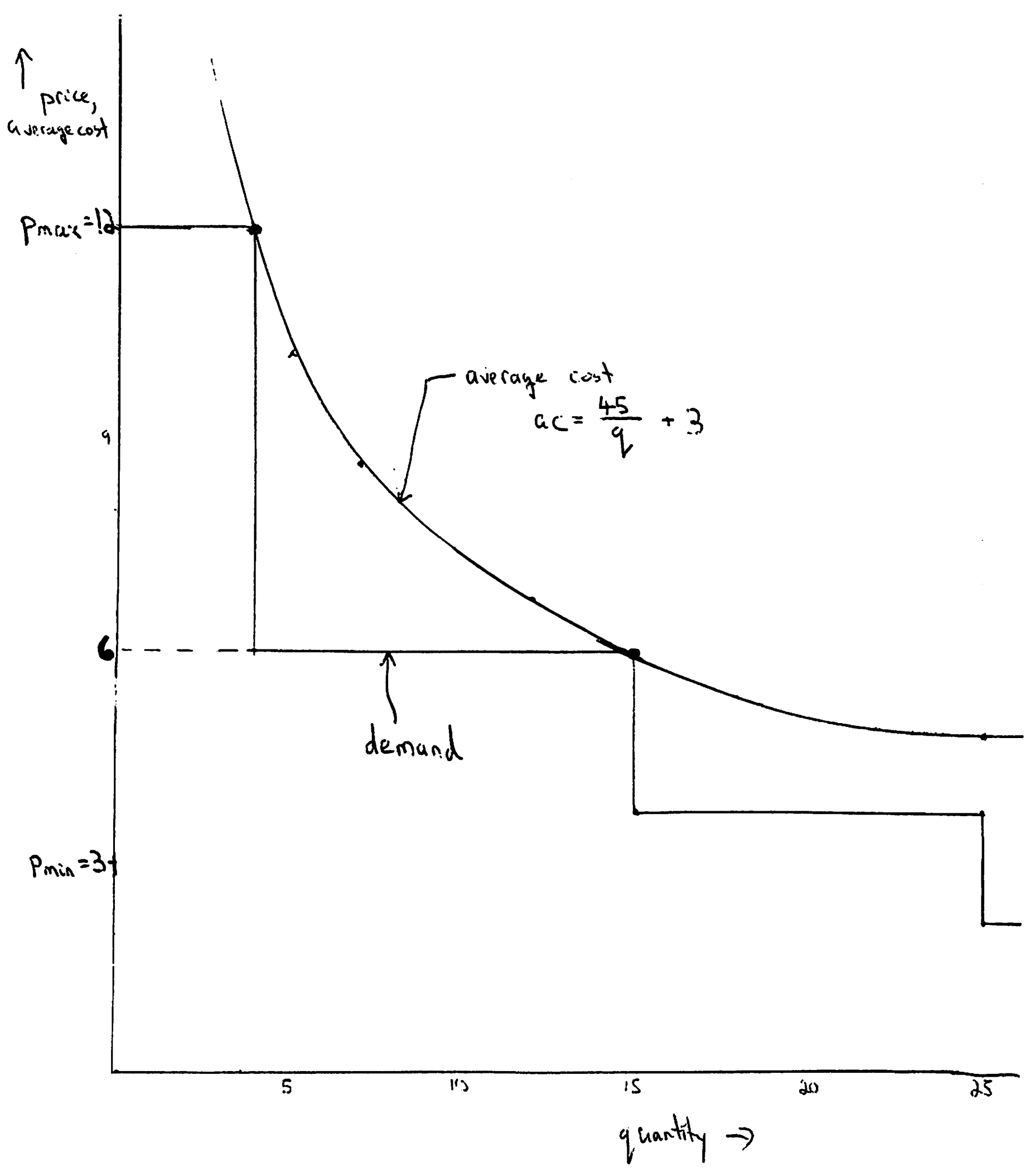

figure 8 


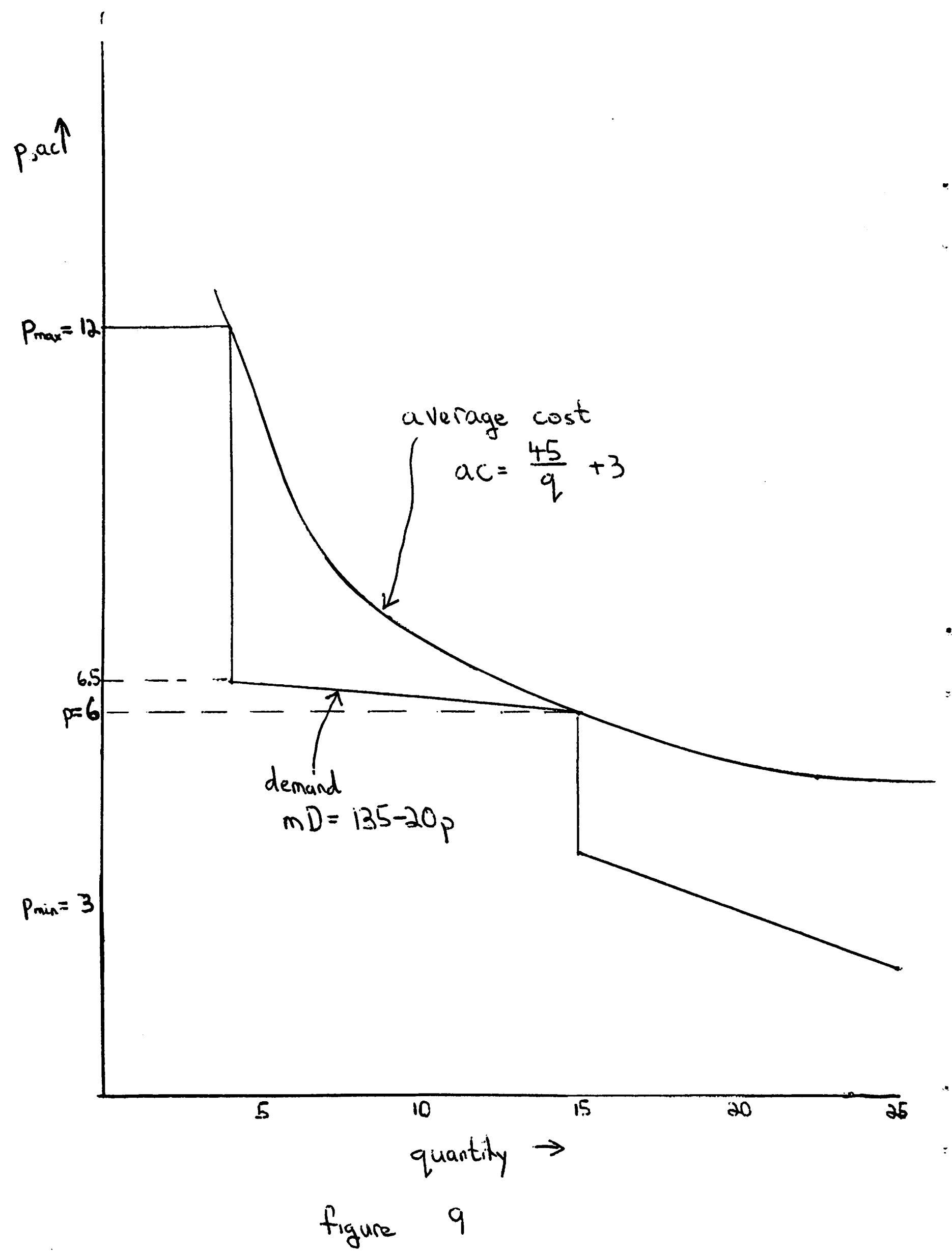

